\title{
Palabras como espejos: la identidad en la poesía de Ana Istarú 1
}

\author{
Alejandra M. Aventín Fontana ${ }^{2}$ \\ Universidad Carlos III, Madrid
}

\begin{abstract}
resumen
La poesía de Ana Istarú se erige a principios del siglo xxi como un imaginario rico y de obligada visita, pues refleja el resultado del proceso histórico de la forja de la identidad del pueblo costarricense tras la independencia de la metrópoli en el marco de su historia literaria, de la centroamericana y en el de habla hispana con toda la problemática que ello implica en territorio tico. Los poemas de La estación de fiebre manifiestan el deseo de independencia e integración de la mujer en el ámbito de lo público a través del cuerpo y de la palabra en el último tercio del siglo xx. Para ello la escritora no duda en denunciar igualmente en su discurso las consecuencias negativas que ha tenido patriarcado.
\end{abstract}

\begin{abstract}
Ana Istarú's poetry began to develop in the early twenty-first century as a rich imaginary not to be missed. It reflects the result of an historical process to forge to identity of Costa Ricans after their independence in the framework of literary history and in particular of Central America and the Spanish-speaking community with all the complexity that this involves in Costa Rica. The poems in La estación de fiebre show a desire for independence and the integration of the woman in the public sphere through her body and through her words in the last third of the twentieth century. Likewise, in her writing Istarú does not hesitate to denounce the negative effects of the patriarch.
\end{abstract}

1 Ponencia presentada en el xx Congreso Internacional de Literatura Centroamericana (ciLca), 2012. Recibido: 30 de marzo de 2011; aceptado: 12 de agosto de 2011.

2 Correo electrónico: alejandraaventin@hum.uc.3m.es

$$
L_{\text {etras }} 50 \text { (2011), ISSN 1409-424X }
$$


Palabras clave: literatura costarricense, poesía costarricense contemporánea, identidad cultural

Keywords: Costa Rican literature, contemporary Costa Rican poetry, cultural identity

\section{Independencia e identidad: Costa Rica ante el espejo de la historia}

Tras la desaparición de la Federación Centroamericana, Costa Rica nace como república libre e independiente en 1848. Para entonces, el país ya había iniciado su actividad exportadora de café a Inglaterra. Este hecho promovió grandes cambios en la economía y en la sociedad costarricense.

Braulio Carrillo, responsable de las administraciones previas a la instauración de la república, promovió en los años treinta un proceso de unificación del país que tenía como objetivo superar los localismos y centralizar en la ciudad de San José la administración nacional. Poco a poco, la urbe josefina fue cambiando su apariencia y sus infraestructuras: el alumbrado de aceite permitió iluminar las calles en las horas de menos luz; se instauró el uso de diligencias al tiempo que proliferaron los hoteles, las tiendas y las casas de alquiler, entre otros. Esta situación generó novedosos patrones de consumo y supuso el ingreso de esta sociedad aldeana «a la modernidad capitalista» y el contacto con «la moderna cultura europea $»^{3}$. La nueva economía costarricense gestada a partir del negocio del café permitió la consolidación de un reducido grupo de familias organizadas a partir del modelo patriarcal que continuaron atesorando un gran poder tras la independencia.

No es hasta la década de los setenta, tras el inicio de los procesos de modernización y liberalización del país, cuando vemos un firme intento por promover la forja de una literatura y un pensamiento costarricense. Esta empresa es llevada a cabo por un grupo selecto de jóvenes intelectuales pertenecientes a una oligarquía y organizados en torno al grupo político conocido como el Olimpo literario. Todos

3 Margarita Rojas y Flora Ovares, Cien años de literatura costarricense (San José: Farben, 1995) 14-15. 
ellos compartían una contradicción que marcará el debate y la evolución de la identidad costarricense: la oligarquía «se movía entre su dependencia económica y cultural de Europa y el afán por consolidar una cultura nacional distinta» ${ }^{4}$.

Jorge Valdeperas insiste en que «una vez que los vínculos coloniales desaparecen, América Latina inicia un desarrollo propio pero sobre un cauce trazado de antemano por intereses muy concretos provenientes ya de Inglaterra, ya de Francia, o, como sucede más tarde, de los Estados Unidos» ${ }^{5}$. Asimismo, Valdeperas asegura que «el papel que en definitiva toca jugar a América Latina durante todo el siglo pasado, en términos de historia mundial, es el de campo de batalla de los intereses expansivos de las potencias europeas» ${ }^{6}$. De hecho, el estudioso subraya que la independencia de Costa Rica, así como la del resto de las antiguas colonias españolas, no son provocadas tanto por las clases criollas hispanoamericanas sino que es el resultado de las tensiones entre España y los países europeos, Francia e Inglaterra, que — según Valdeperas - no dudaron en financiar una parte de esta empresa ${ }^{7}$.

Estas reflexiones profundizan en la problemática existente en torno a la independencia y ayudan a entender mejor el inicio de la discusión sobre la identidad que en el caso de Costa Rica posee otras peculiaridades. Dice Carlos Cortés: «Somos diferentes: sin indios, sin violencia, sin clases sociales, sin ejército, por un lado; con una

4 Rojas y Ovares, 32. La influencia de los intereses económicos de la nación en la fragua de su identidad tuvo un gran peso en los intelectuales y escritores a partir de entonces. En este sentido fue vital la aportación realizada por la llamada generación del Repertorio a través de su obra y su pensamiento. Sus líneas generales quedarían registradas en la revista Repertorio Americano cuya publicación comenzó en 1919 y se extendió hasta 1958. La revista nace en plena crisis económica y política con un «afán didáctico y espíritu popular», Rojas y Ovares, 62. El Repertorio Americano refleja un gran cambio en relación con el Olimpo literario: «Los intelectuales anteponen la necesidad de defender unos valores espirituales frente al progreso económico», 61 .

5 Jorge Valdeperas, Para una interpretación de la literatura costarricense (San José: Editorial Costa Rica, 1979) 19.

6 Valdeperas, 19.

7 Valdeperas, 18. 
población blanca, con una estabilidad democrática, con educación para todos, con paz, por el otro» ${ }^{8}$.

Efectivamente, la nación costarricense, a diferencia del resto de las culturas de los países centroamericanos, no posee un sustrato indígena sino que ha basado los pilares de su imaginario en la cultura española asimilada durante el periodo colonial primero y más tarde en el diálogo con esta última y con la hispanoamericana9 ${ }^{9}$. Esta dinámica tendrá una clara repercusión en la literatura, pues su intento por ahondar en el espíritu autóctono oscilará tras la Independencia entre la mímesis - el escritor costarricense busca en patrones literarios proporcionados por el costumbrismo y el modernismo dar forma a la realidad propia y cae a menudo en la forja de estereotipos y de «una imagen ideal e idealizada de la nación» ${ }^{10}$ - y el deseo de una ruptura sin una aparente dirección. En el ámbito de la poesía, ésta dura hasta la tardía irrupción de las vanguardias a mediados de los años cuarenta con Isaac Felipe Azofeifa (1909-1997) y Eunice Odio (1922-1974); y encuentra en Jorge Debravo (1938-1967) el engranaje y la voz auténtica de lo costarricense para decirse ya en la década de los sesenta en un movimiento que lo lleva a reencontrarse con lo primigenio para proyectar desde el amor la lucha por el diálogo anclado en la justicia universal.

Sin embargo, no es hasta la década de 1980 cuando revela la urgente necesidad de comenzar a dialogar con los signos de su tiempo sin temor, tal y como muestra el proyecto poético de Ana Istarú. Un diálogo que la escritora articula desde la contemplación del mundo circundante y la realidad cotidiana en su producción inicial, y que posteriormente, impulsa con el espíritu novedoso y transgresor de buscarse y buscar lo costarricense, tal y como ella misma explica, a partir de la narración de «aquellas contradicciones invisibles para confrontarlas

8 Carlos Cortés, La invención de Costa Rica (San José: Editorial Costa Rica, 2003) 29.

9 Carlos Francisco Monge, Antología crítica de la poesía de Costa Rica (San José, Editorial Universidad de Costa Rica, 1992) 9.

10 Carlos Francisco Monge, El vanguardismo literario en Costa Rica (Heredia, Costa Rica: Universidad Nacional, 2005) 82. 
con el lector, sensibilizarlo e intentar modificar una conducta social» ${ }^{11}$. En la misma línea de Istarú - a quien Carlos Francisco Monge incluye dentro de la tercera generación de postvanguardia ${ }^{12}$ — destacan igualmente las aportaciones hechas por el propio Monge, Lil Picado, Diana Ávila, Gerardo Morales o Juan Antillón ${ }^{13}$.

Por otro lado, frente a la historia del siglo xx que ha salpicado la cintura de América de dictaduras, masacres y violencia, en Costa Rica, a excepción de episodios puntuales — la huelga bananera de 1934 y la breve guerra civil de 1948 causada por un fraude electoral- la democracia ha reinado y ha visto reforzado su papel de garante de la paz y de la educación, al tiempo que ha sido testigo de la consolidación de una clase media, gracias en parte a las políticas culturales e intervencionistas del estado promovidas desde mediados del siglo xx hasta la década de 1980, época en la que se consolida el neoliberalismo estatal. Cortés se refiere así a la democracia tica no tanto como un proceso sino como «un estado, acabado, final» ${ }^{14}$.

Por lo tanto, Costa Rica parece a los ojos de sus habitantes diferente y ciertamente lo es por muchas razones, y no solamente por aquellas a las que Cortés alude, algo que ha complicado la buena sedimentación de la identidad nacional tras la Independencia primero y que ha marcado su literatura en general y su poesía en particular después.

En su ensayo «El imaginario nacional: mitos de integración, mitos de exclusión», ahonda en las raíces de este sentimiento de diferencia. Explica Cortés que en la historia centroamericana siempre ha existido un eje de dominación norte-sur, algo que ha tenido una clara repercusión en el pueblo tico. Así, mientras que en el período precolombino fue el Imperio Azteca y en el colonial fueron España

11 Esther Quintana y Alejandra Aventín, «Palabras como imanes: entrevista a Ana Istarú», Hispanic Poetry Review VIII, 2 (2009): 95.

12 Carlos Francisco Monge, La imagen separada: modelos ideológicos de poesía costarricense (1950-1980) (San José: Instituto del Libro, 1984) 29.

13 Selena Millares, La maldición de Sheherazade. Actualidad de las letras centroamericanas (Milán: Bulzoni, 1997) 55-56.

14 Cortés, 39. 
e Inglaterra, posteriormente, en el periodo republicano, Guatemala, Inglaterra y Estados Unidos se erigieron como los nuevos ejes de dominación. Esta circunstancia promovió que el país se replegara sobre sí mismo. De esta manera, si ya de por sí Centroamérica parece haber consolidado su carácter de margen de Hispanoamérica en el siglo $\mathrm{xx}^{15}$, el país costarricense lo ha hecho como ínsula dentro del Istmo. De hecho, tras su descubrimiento, «costa rica» como la llamó Colón, fue durante mucho tiempo la provincia más pobre del Reino de Goathemala ${ }^{16}$.

Sin embargo, a estas circunstancias históricas hay que sumar la presencia de uno de los mitos fundadores al que Cortés dedica una especial atención: el mito de la Arcadia tropical. El Valle Central - que constituye a su vez la meseta central de Costa Rica y que albergó los primeros asentamientos de la población costarricense- es un espacio idílico cuya condición geográfica de puente entre el norte y el sur ha contribuido a generar en sus habitantes un sentimiento de ruptura externa y separación ideológica interna. Se crea así, poco a poco, para lo que luego va a ser la nación de Costa Rica, el espejismo de que el pueblo tico vive inmerso en lo que Carlos Monge Alfaro ha llamado la «edad de oro del campesino» ${ }^{17}$ que parece atar el espíritu de lo autóctono a una imagen fija, suspendida en el tiempo. Este mito, así como el de la Arcadia tropical, parece verse reforzado por la continuidad del régimen democrático en la historia nacional.

Por su parte, el poeta y ensayista Carlos Francisco Monge ha dedicado varios estudios en los tres últimos decenios en los que

15 En la obra Más allá del boom: literatura y mercado, Elizabeth Garrels recoge en el texto titulado «Resumen de la discusión», aquellas cuestiones abordadas por críticos y escritores en un encuentro organizado por el Latin American Program del Woodrow Wilson International Center for Scholars (Smithsonian Institution, Washington) en la década de 1980. Garrels señala cómo David Viñas se había referido a Centroamérica en relación con América Latina: «América central constituía el silencio dentro del discurso latinoamericano» junto a Brasil y a las mujeres; en Elizabeth Garrels, «Resumen de la discusión», en Ángel Rama, ed., Más allá del boom: literatura y mercado (Buenos Aires: Folios, 1984) 323.

16 Cortés, 18.

17 Carlos Monge Alfaro, Historia de Costa Rica (San José, Trejos, 1977). 
profundiza sobre la cuestión de la identidad costarricense ${ }^{18}$. Monge se refiere a ella como imagen separada y habla del «hambre de claridad del costarricense» ${ }^{19}$. Esta crisis ideológica, que surge de la separación del ser de la reflexión y el análisis de las circunstancias que lo rodean, es, según el costarricense, un problema que comparten el creador y la crítica literaria tica. En este contexto, Monge habla de los versos de Ana Istarú como una poesía que, al igual que la de sus coetáneos, adopta la necesaria empresa de establecer nuevas relaciones «con los signos de la historia, cuyo sentido aparece sombreado e incierto» que en el caso de la poeta «no muestra temor por sustituir la utopía por la interrogación $»^{20}$.

Carlos Rafael Duverrán habla de la evolución de la poesía costarricense y de cómo esta refleja el conflicto del ser costarricense, ya palpable antes de la década de 1980:

Nuestra poesía ha carecido de grandes maestros y de fuertes movimientos progresivos. [...] A nuestra lírica le ha faltado el sentido de la universalidad, no en el aspecto de temas o motivos, sino en la sintonía cordial con el mundo, en la necesaria fertilización espiritual que en otros climas ha producido obras extraordinarias ${ }^{21}$.

Una sintonía a la que Carlos Cortés, en «Fronteras y márgenes de la literatura costarricense», tilda de inviable al referirse a Costa Rica como una «ínsula rarísima» que ha basado su sistema simbólico en «el olvido — no la amnesia, que es la pérdida total de la

18 Carlos Francisco Monge es uno de los pensadores costarricenses que más títulos ha dedicado a la reflexión sobre la identidad y la literatura de su país y entre los que cabe destacar: La imagen separada. Modelos de la poesía costarricense (1984); la introducción elaborada para la obra Antología crítica de la poesía de Costa Rica (1993) y la redactada para la compilación titulada Costa Rica: poesía escogida (1998); asimismo resultan igualmente relevantes las colecciones de ensayos La rama del fresno (1999), El vanguardismo literario en Costa Rica (2005) y Territorios y figuraciones (2009).

19 Monge (1984) 29.

20 Carlos Francisco Monge, Costa Rica: poesía escogida (San José: Editorial Universitaria Centroamericana, 1998) 16.

21 Carlos Rafael Duverrán, «Prólogo» en Laureano Albán, Carlos Luis Altamirano y Arturo Montero, eds., Poesía contemporánea de Costa Rica (San José, Editorial Costa Rica, 1973) 16. 
memoria, sino la dismnesia, la debilidad de la memoria, que es recordar para olvidar, para ocultar, para negar-, el disimulo, la hipocresía, el silencio, el consenso sublime, el conflicto y la subversión ideológica» en un contexto en el que «la intimidad» se confunde «con el pecado social» $»^{22}$.

El intento que hacen Cortés, Monge o Duverrán, pero también Carmen Naranjo, Álvaro Quesada Soto y Jorge Valdeperas, por profundizar en la problemática que rodea la identidad costarricense desde una nueva óptica más crítica hoy, encuentra en la obra poética de la escritora Ana Istarú un ámbito crucial y fecundo. En sus versos, Istarú retrata esa imagen separada y tras aceptar su condición de «ínsula rarísima» al igual que Cortés ${ }^{23}$, la combate asumiéndola con dolor, sin miedo al interrogante, al retrato y a la denuncianecesaria.

En el poema «Este país está en el sueño», se erige como portavoz de un pueblo que para cambiar el rumbo de la historia y comenzar a escribir la suya propia ha de enfrentarse a la existencia de una fractura, de esa distancia entre la realidad y el imaginario construido hasta el momento:

yo sé que no hubo historia si acaso fuimos rumores de maledicencias un trillo nebuloso la huérfana del mundo [...] pero somos pocos en saberlo este país

está en el sueño que nos toca sobre la faz del mundo que nadie me lo arranque es todo cuanto tengo mas este corazón para simiente ${ }^{24}$

22 Carlos Cortés, «Fronteras y márgenes de la literatura costarricense», Cuadernos Hispanoamericanos 648 (2004): 20-21, 26.

23 Cortés (2004) 20.

24 «Palabras como imanes: entrevista a Ana Istarú», 94. 


\section{La poesía de Ana Istarú y el reflejo de la identidad}

En el transcurso de una entrevista de 2007, Istarú se refiere así a la recién citada composición incluida en su obra La muerte y otros efímeros agravios que data de 1989: «Cuando escribo Este país está en el sueño, de alguna forma intento aludir a la actitud del costarricense de percibir su propio país como una especie de arcadia, paraíso perdido». Y más adelante puntualiza: «pienso que los costarricenses nos hemos ensoberbecido con esta visión un tanto ilusoria porque nos impide ver una serie de contradicciones que intento evidenciar en lo que escribo, particularmente en lo que más me interesa que es la inequidad de género que existe» ${ }^{25}$.

La poesía de Istarú ha de ser concebida dentro de la problemática de la identidad costarricense como una poesía de praxis. Ésta se encuentra regida por una doble transgresión que podemos hallar en los seis poemarios que integran su producción hasta el día de hoy.

La primera - y a la que ya hemos aludido - es la de la costarricense que llama al despertar a su pueblo con ternura pero igualmente con la fiereza de una madre que no teme reprender a un hijo. En La muerte y otros efímeros agravios encontramos igualmente la composición «El hambre ocurre» en la que Istarú aspira a denunciar el silencio y el consenso ideológico metafóricamente:

el hambre ocurre

esto lo escribo en Costa Rica

estamos en septiembre ochenta y cinco

pero resulta

la muerte es aquí católica apostólica

el sueño en que moramos no resiste

este grillete

así nadie comenta

25 Cortés (2004) 20. 
el hambre queda en rasgo de mal gusto

la paz

aquí la paz se nutre con la sangre ${ }^{26}$.

El segundo tipo de transgresión presente en los versos de la escritora es el llevado a cabo como mujer que reivindica en términos de complementariedad su presencia en la esfera pública y denuncia el daño procurado por el patriarcado no solamente en la hembra sino igualmente en el varón. Esta dinámica, al igual que la anterior, recorre toda su obra desde sus primeros libros en los que vemos cómo una jovencísima Istarú aborda la desigualdad entre la mujer y el varón en «Primer silabario», un texto incluido en Poemas abiertos y otros amaneceres (1980), refiriéndose con dulzura al padre y a la madre. Sin embargo, en los últimos versos de la composición, la poeta se muestra contundente en su deseo por contribuir a un cambio: «Papá lee. Mamá lava./ Yo voy a romper, mamá, alfileres y candados» ${ }^{27}$.

El tema de la libertad es uno de los ejes vertebrales de este tercer poemario. En la composición «Para ser mujer» leemos: «Me dieron/ mis dos brazos de mujer/ pero no me dijeron cómo romper los cerros» ${ }^{28}$. Pero la libertad personal no es únicamente la libertad del yo de la poeta sino igualmente la libertad de otras mujeres que padecen la soga del patriarcado: «Vengo por lo que es mío,/ de mi tenue sudor,/ de mi vientre./ Por mi libertad de siglos/ clavada en las paredes ${ }^{29}$. En este punto cabe señalar que en la poesía de Ana Istarú la cuestión del género - que aparece claramente concebido como una construcción cultural- es entendida, a diferencia de la escritura de otras coetáneas, como una categoría que ha afectado igualmente al varón. En La estación de fiebre (1983), Istarú se refiere a los genitales masculinos con ternura y delicadeza y le brinda varias

26 «El hambre ocurre», en La muerte y otros efímeros agravios, 17.

27 «Primer silabario», en Poemas abiertos y otros amaneceres, (San José, Editorial Costa Rica, 1980), 12.

28 «Para ser mujer», en Poemas abiertos y otros amaneceres, 13.

29 «Por mi libertad» en Poemas abiertos y otros amaneceres, 20. 
composiciones que nacen de laintimidad compartida con el amante. En el poema «xxviii» leemos:

pene de pana

pene de flor del destinado mío

empuñadura del sol

envidia del anturio

aguda palabra

mástil de las estrellas

garza despierta

garza dormida ${ }^{30}$.

\section{La patria íntima como lugar de enunciación}

El impulso transgresor istariano encuentra en la patria íntimatema muy frecuentado en Centroamérica y en Costa Rica, tal y como señala Selena Millares ${ }^{31}$ _ , un espacio en el que fundar su deseo por reparar la imagen separada a la que se refiere Monge y por combatir la aludida dismnesia, «el consenso sublime», las dinámicas del aparato ideológico nacional o la intimidad entendida como pecado social — problemas a los que alude Cortés ${ }^{32}$ — a través de una fusión conciliadora que oscila entre la contemplación, el diálogo con el mundo y la defensa de lo solidario. Estas tres líneas quedan materializadas en un engranaje poético signado por la constante presencia del amor y lo elemental. Istarú perfila en una escritura poética desde el margen, los contornos de la patria que quedan abiertos al mundo, a través de la vida como celebración de amor y sus misterios en un periodo de crisis e incertidumbre:

30 «xxviii», en La estación de fiebre, en Ricardo Bada, ed., La estación de fiebre y otros amaneceres, Madrid, Visor, 1991, págs. 53-54. En el transcurso de una entrevista, la escritora se refiere al miembro masculino: «El pene es siempre visto o como vergonzoso, bochornoso, sucio, pero sobre todo como un arma agresora. Entonces yo quería reivindicar la delicadeza, la suavidad, la ternura de los genitales masculinos tienen y que no han sido tampoco llevados normalmente en la literatura»; en «Palabras como imanes: entrevista a Ana Istarú», op. cit., pág. 107.

31 Selena Millares, La maldición de Sheherazade. Actualidad de las letras centroamericanas 1980 1995, (Roma, Bulzoni, 1997), 55-56.

32 Cortés (2004) 20-21. 
Ahora que el amor

es una extraña costumbre,

extinta especie

de la que hablan

documentos antiguos,

y se censura el oficio desusado

de la entrega; $[\ldots]$

Rescato la palabra primera:

del útero, y clásica y extravagante

emprendo la tarea

de despojarme.

Y amo» ${ }^{33}$.

En la producción inicial de Ana Istarú, Palabra nueva (1975), Poemas para un día cualquiera (1977) y Poemas abiertos y otros amaneceres (1980), encontramos composiciones en las que la poeta muestra su inquietud por desgranar el misterio de la vida y del amor propio y ajeno. En «Autobiografía» leemos: «Soy una sombra diminuta/ entorpeciendo la vasta cavidad del tiempo ${ }^{34}$ para posteriormente convertir sus versos en un escenario capaz de humanizar y naturalizar los espacios públicos de su San José natal de los que la poeta se apropia y transforma e integra en su patria íntima como ámbito desde el que practicar el intimismo testimonial y profesar poéticamente su compromiso con el entorno. La marcada distinción entre lo privado y lo público, categorías asociadas con el patriarcado, parece dejar de existir gracias a los lazos de la fraternidad y al amor por lo natural que triunfantes convierten al mundo en territorio regido por $\operatorname{Eros}^{35}$ :

33 «iv», en La estación de fiebre, 53-54.

34 Este primer poemario de Istarú no se encuentra paginado, por lo que dicho dato no constará tampoco en las sucesivas alusiones a los poemas que contiene la obra, que tal y como se indica en la misma se trata de una «Edición hecha en celebración del día en que la autora de estos poemas cumplió Quince Años»; en Ana Istarú, Palabra nueva, San José, 1975.

35 Eros ha de entenderse en este contexto como el instinto de la vida que en el discurso freudiano se encuentra vinculado con la muerte. Tal y como explica Marcuse «La vida es la fusión de Eros con el instinto de la muerte», en Herbert Marcuse, Eros y civilización (Barcelona: Ariel, 1981) 86. Por su parte, Sonia Mattalía dice sobre la experiencia literaria que «ha sido y es escena privilegiada de 
San José tiene el color tierno

de los pájaros pequeños. [...]

Amo la gente que mira las ventanas de las tiendas,

que baña calles y aceras

o grita luz en el mercado, [...]

San José tiene la savia gris como los nidos, pequeño islote de pluma, rinconcillo dorado en el huerto del mundo ${ }^{36}$.

Sin embargo, en estos primeros títulos las calles, la naturaleza y la gente quedan entremezcladas en su deseo por contemplar y dialogar con el entorno con el ímpetu por cuestionar los valores heredados:

voy a dejar mi traje de virgen

en la esquina

mi fatigoso empeño

de miedo y de horarios, $[\ldots]$

para escapar de todo

lo que he aprendido

y empezar de nuevo

a no saber nada ${ }^{37}$.

Si la producción inicial encuentra en la admiración y la interlocución con el mundo y el cuestionamiento del patriarcado su anclaje discursivo por excelencia, a través de la reivindicación de una necesaria humanización del espacio propio y compartido como ámbito en el que

la representación de la subjetividad; una puesta en acto no sólo de los conflictos individuales y / o epocales, sino de la representación de la lucha originaria en el ser humano entre Eros y Thanatos»; en Sonia Mattalía, Máscaras suele vestir. Pasión y revuelta: escrituras de mujeres en América Latina (Madrid: Iberoamericana, 2003) 34. La literatura, y la poesía en particular, es por lo tanto un ámbito que refleja las tensiones y los cambios que se producen en la sociedad. Éste es por lo tanto un espacio clave para la expresión del autor y en el caso de Ana Istarú arena donde narrar y practicar una insurrección que lleve a un cambio necesario para la sociedad costarricense.

36 «San José», Ana Istarú, Poemas para un día cualquiera (San José, Editorial Costa Rica, 1976) 53.

37 «No saber nada», en Poemas abiertos y otros amaneceres, 137. 
las convenciones sociales dañinas son rechazadas, La estación de fiebre (1983) nos brinda un territorio en el que la patria íntima es fraguada y dicha desde el impulso de Eros vivido en su versión más carnal: por la presencia de un erotismo arrollador y novedoso que indaga en la fractura de la identidad costarricense cuestionando los ordenadores de sentido imperantes y rechazando el consenso sublime de aquellos que habían negado a la mujer la expresión pública del gozo ${ }^{38}$. A lo largo de treinta y tres estaciones, la poeta nos acerca en primera persona al encuentro íntimo con el amado. La geografía corporal y las dinámicas del deseo son plasmadas en un estilo que a menudo emparenta con el barroco por el ingenio y el preciosismo de las imágenes que nuevamente se encuentran marcadas por la presencia de loelemental:

para la noche canto

te deshojo

eres la dalia que se eleva

la armonía de metales que faltaba

te vienes al rocío por mi cauce

éramos en plural

estamos uno ${ }^{39}$

No obstante, al igual que sucede con toda la producción istariana, este poemario dista de estar exento de la crítica explícita a la moral convencional con la que la escritora inicia La estación de fiebre. En el poema «iii» leemos:

Este tratado apunta

honestamente

que el pudor y su sueño

no encuentran mejor dueño

38 La estén de fiebre, obra merecedora del premio de poesía Educa en 1982 por su «alta temperatura erótica» y el «infalible gobierno de la forma» (en La maldición de Sheherazade, 65) promueve según Carmen Naranjo «la inversión del elogio erótico»; en Carmen Naranjo, Mujer y cultura (San José: $\left.e_{\text {duca }}, 1990\right) 190$.

39 «xxiv», en La estación de fiebre, 83. 
que el rincón apacible de la vagina

y me destina a una paz virginal

y duradera ${ }^{40}$.

Si hay una colección de poemas que indaga en la denuncia al tiempo que explora la verticalidad de la contrapartida de Eros, el fin de la vida, Tánatos, es La muerte y otros efímeros agravios (1989). Tal y como señala la profesora Selena Millares en la obra «se delata una honda conciencia de la muerte que habita la vida [...] y la certidumbre de luz condenada al ocaso condiciona una pasión feroz $\gg^{41}$ por ésta. En «Instrucciones para el difunto» Ana Istarú aborda con sordidez e ironía el tema de la muerte. La transgresión es practicada en un doble sentido: la primera hacia el individuo a quien da instrucciones para cuando fallezca, pero igualmente hacia la familia que aparece retratada en el poema en clave igualmente irónica y ridiculizada en versos como «-No toque al cadáver-,/ atentos como están a su tristeza $\gg^{42}$. Al hablar de esta manera de la muerte, Istarú está atentando contra la intimidad como pecado social. El lector queda expuesto a la contemplación del cuerpo ante la mirada de la familia y el proceso de putrefacción relativamente detallado, que de nuevo nos conduce a la disolución del ámbito de lo privado y de lo público.

La muerte y otros efímeros agravios pone de manifiesto la lucha contra el consenso sublime costarricense al denunciar su falta de conciencia social y reivindica la solidaridad más allá del propio territorio. Istarú rechaza el mito de la Arcadia tropical y se atreve a señalar al pueblo costarricense para reparar la imagen separada; para que ésta se convierta en significante y comience a ser significado y piel que se siente parte de un continente que en los últimos decenios

40 «iii», en La estación de fiebre, 51.

41 «Ana Istarú: la insurgencia de Eros», en Ángeles Encinar, Eva Löfquist y Carmen Valcárcel, eds., Género y géneros I. Escritura y escritoras iberoamericanas (Madrid: Universidad Autónoma de Madrid) 112.

42 Ana Istarú, «Instrucciones para un difunto», La muerte y otros efímeros agravios (San José, Editorial Costa Rica, 1988) 28. 
ha sido testigo del hambre y la violencia. En la composición «Viene volando un tiempo de cañones» leemos:

Este país

pensó poder planear sobre la sangre

inmaculadamente.

Dijo: mi castidad, mi clara trayectoria.

No vivo en este barrio del tormento.

No son parientes ${ }^{43}$.

La composición termina con una declaración de la propia poeta quien abre sus versos y su patria íntima al mundo:

Estoy aquí, asida al universo. Amo a la gente, la que no sabe y la que en cambio otorga su condición viviente, cae en la lucha.

Mi pueblo no es un pueblo ni una raza.

$\mathrm{Su}$ error estriba en las fronteras. ${ }^{44}$

En Verbo madre (1995), la mirada de la poeta se retrotrae a la sabiduría de la naturaleza de la mujer y sus vivencias más íntimas y reelabora el sentido de la existencia más allá de lo orgánico, si bien lo incluye también. Se trata de un plegarse para contemplar cómo nace y muere la vida. Habla de su experiencia como madre pero también de la pérdida de quien le dio esta vida. En «Noticias de casa» la poeta se pronuncia al respecto con tristeza y resignación por su marcha: «estamos bien y tengo la mirada partida/ y todo lo que como es el plato de tu muerte» ${ }^{45}$.

Verbo madre consolida el signo de la lírica istariana como transgresor, pues en sus versos, la costarricense reivindica la naturalidad

43 Istarú, «Viene volando un tiempo de cañones» (1988) 51.

44 «Viene volando un tiempo de cañones» (1988) 52.

45 «Noticias de casa», en Verbo Madre (San José: Editorial Mujeres, 1995) 58. 
de la experiencia de la maternidad desde el momento de la concepción, abordando el proceso de gestación, el alumbramiento y la lactancia con total libertad y orgullo y recreándose en el gozo de su ser mujer, tal y como constata en «Yo, la hembra fiera»:

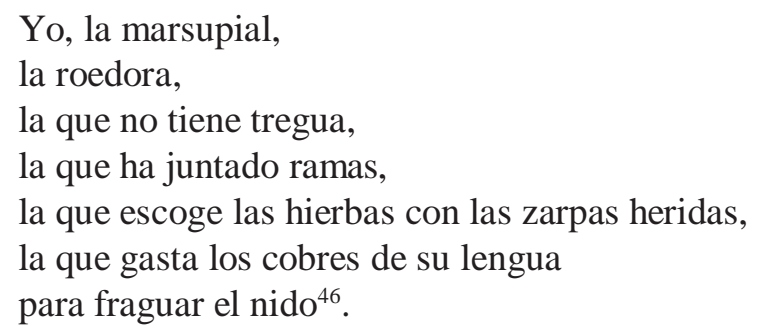

En Istarú, la maternidad y las sensaciones físicas y espirituales que nacen de ella son vividas desde la contemplación atenta y el diálogo con la naturaleza entrevisto como un instinto capaz de abrir la puerta al misterio de la vida, tal y como vemos en la composición titulada «La doncella sagrada»:
Una mujer
presiente que el eco de la tierra en sus entrañas.
Agita su pandero, su cúpula de carne.
La están nombrando a voces ${ }^{47}$.

Tánatos vuelve a estar presente en Verbo madre, en los versos que Istarú dedica a su propia progenitora en esta obra. La experiencia de su muerte es plasmada desde el interrogante que ora es dolor ora es palabra viva capaz de crear un espacio que le permita a la poeta despedirse de quien la vistió con el traje de la vida acompañándola en su última travesía; aquella que la llevará al sueño eterno: «adiós pequeña/ duerme/ no habrá bestias feroces en la oscuridad» ${ }^{48}$.

\footnotetext{
46 «Yo, la hembra fiera», en Verbo Madre, 15.

47 «La doncella sagrada», en Verbo Madre, 16.

48 «Una hija conduce a su madre hasta el sueño», en Verbo Madre, 61.
} 
Sin embargo, la esperanza que atraviesa la lírica istariana erige a Eros como victorioso: el amor por la vida y sus dinámicas, la lucha por la vida y su defensa conducen a la poeta a un camino forjado a partir de la contemplación, la interrogación y la necesaria transgresión de una mujer que escribe desde su cuarto propio, como diría Virginia Woolf, convencida por el poder cósmico y espiritual de lo femenino, pero por encima de eso, del ser costarricense como imagen reparable e imaginario necesario y poderoso en el siglo xxi. En su nombre, Istarú pinta versos y vive con valentía:

la patria vuela

el viento está de púas

pienso en el rayo

miro enamorada a los que pasan

soy mujer

soy la hija de tantos y de todos [...]

no voy a ser la moribunda

tomo la crin la patria ebria

galopa vuelva desbocada

no me intimida el precipicio

prendo el clamor de los que luchan

juro vivir por los que pasan

enamoradamente y con victoria ${ }^{49}$.

49 «No voy a ser la moribunda», en La muerte y otros efímeros agravios, 65-67. 